\title{
Transformation in transportation?
}

\author{
Merja Hoppe • Andreas Christ • Alberto Castro • \\ Martin Winter • Tiina-Maria Seppänen
}

Received: 10 July 2014 / Accepted: 13 October 2014 /Published online: 20 November 2014

(C) The Author(s) 2014. This article is published with open access at Springerlink.com

\begin{abstract}
The world of transportation is changing. Due to increasing mobility demand, challenges like financing, dealing with emissions and volatile oil prices are accentuated. Decision-makers in the areas of policy and planning have to address these challenges and have try to develop a transportation system capable of meeting the future needs of society and the economy. Thus there is a need for conceptions of the future system as guidelines for decisions. Besides developing new mobility solutions, adapting to a changed world of energy dependencies and addressing social developments will be the main tasks for decision-makers. This paper shows the results of future-oriented research based on the qualitative analysis of megatrends, which were used to describe the main trends setting the direction for future development in transportation and their likely effects. Based on the question of whether there is a transformation - a process of actively supporting change in the transportation system according to trends and changes in frame conditions - going on, analysis of current policies provide a different conclusion. The change in transportation appears as a process of substitution within the boundaries of the fossil-fueled world rather than as transformation in the sense of a fundamental change. Finding alternative development paths would require a perception of transformation as a process of actively shaping and redirecting the system by anticipating and addressing future challenges. Starting points and impulses in this context are rare and to be found in strategies of China, in other parts of Asia and in Europe. The approach of using recent, established and prospective, uncertain megatrends with their potential impact as a basis to provide a future perspective on change processes turned out
\end{abstract}

M. Hoppe $(\bowtie) \cdot$ A. Christ $\cdot$ A. Castro $\cdot$ M. Winter · T.-M. Seppänen INE Institute of Sustainable Development, ZHAW Zurich University of Applied Sciences, Technikumstrasse 9, P.O. Box, 8401, Winterthur, Switzerland

e-mail: Merja.hoppe@zhaw.ch to be an appropriate way to identify starting points for further research, which should integrate quantitative analysis. Furthermore, additional future- oriented research on megatrends would be needed to accommodate the complexity of the systemic perspective.

Keywords Megatrends · Transportation system · Transportation technologies $\cdot$ Transportation concepts

\section{Transformation of transportation}

Over the last few decades, mobility and transportation have had to face a process of change which is still continuing. Demand for mobility, volume of traffic and, along with this, the need for transportation infrastructure are further increasing, while a rising and highly volatile oil price is challenging the economy and society. At the same time, decision-makers in policy and planning have to deal with a financial crisis, resulting in a lack of money for the maintenance and expansion of transportation infrastructure, and they have to address climate change by reducing $\mathrm{CO}_{2}$ emissions and energy consumption. As $\mathrm{t}$

he situation is expected to deteriorate, leading to a fundamental change, a transformation of the transportation system is expected to occur, which at the same time should affect our understanding of mobility.

As with every change, decision-makers in transportation, spatial and economic planning and policy need to react to the change process. The transportation system has to be adapted and designed according to the new situation. 'Transformation' in this context is used as a term describing not only a change process driven by different socio-economic and political drivers, but a process in which decision-makers are aware of an ongoing change and can thus shape the process actively according to the goals they have set. 
As the direction and results of the change process are not clear, decision-makers have to deal with uncertainty, which is mainly due to the complexity of the system. Both demand and supply are driven by high-impact trends which influence each other and thus lead to an unclear situation. To decide and act successfully in this complex environment, decision-makers need to gain a deeper understanding of the development and a clearer picture of the future - and to reduce uncertainty.

Knowledge about the future, as a basis for decision-making, is lacking. Even though uncertainty is unavoidable, defining the field of uncertainty can help to deal with challenges and risks, and even to identify opportunities. To shed light on the field of uncertainty provides insights on where to focus attention, decisions and actions to shape the future development of transportation and mobility.

A systematic analysis of relevant drivers, trends and their recent and future impacts of the change process help not only to provide a basis for decisions, but also to create future scenarios. To do this, knowledge about recent trends affecting transportation with their likely outcomes and their interdependencies is needed. The paper suggests a qualitative approach to systematically analyzing trends relevant for the future by using the concept of megatrends, as fundamental, long lasting, global or international transformation processes with a certain direction, including the economic and the socio-cultural dimension and affecting multiple aspects of life [5]. The work, based on the outcomes of the EU-funded project OPTIMISM, combines two steps:

1. Megatrends were used to describe possible future outcomes of ongoing developments along with their consequences and to try to characterize the process of change. To distinguish their relevance and impacts they have been classified according to their character of established or more uncertain trends.

2. Based on the assumption that megatrends can be used to create a decision basis to shape/lead the transformation process actively, they were used to identify signs of promising evolution and starting points for action.

In the early 1980s, John Naisbitt created the term "megatrends" to describe several transformations taking place in the USA and worldwide [34], including the decreasing influence of industry and increasing influence of information on societies, the role of the globalized economy, the transition from centralized to decentralized governments as well as from representative to participative democracy [28]. From then on, megatrends have been mapped in very different research areas, including transportation. One of the first publications introducing the concept of megatrends in transportation research appeared in 1984 with an analysis of likely changes in public transportation in terms of ownership, operation and competition. Megatrends not only envisage future developments in a certain sector, they also demonstrate the constant transformation of our current society and the interrelationship between the different global transformation processes. Indeed, the European Environment Agency stated that megatrends, many of them out of European control, are highly interdependent and "have significant consequences and potential risks for the resilience and sustainable development of Europe's economy and society".

Transportation is embedded in this changing world. Therefore, it is affected by several factors such as economic trends (e.g. globalization, economic growth, limited financial resources), technological trends (e.g. IT and ICT), demographic trends (e.g. aging, decrease in household size, immigration) and social trends (lifestyle changes, environmental concerns, security concerns, social exclusion) [2]. An international survey focusing on decision-makers revealed that "support of behavioural change policies depends on the type and level of governance of the region, on its technological focus and on cultural and historical factors" [9]. The analysis of transportation megatrends also faces some challenges deriving from the uncertainty of future research. The European Environment Agency stated that a better understanding of the linkages between ongoing megatrends is needed and a study noted, after constructing a quantitative model of freight transport for 2050 in Europe, that "further research is recommended to screen preferable technological roadmaps from the broad range of available futures" [23].

Megatrends can be classified by their duration and continuity into the two groups:

1. Recent, established and stable trends: their evidence is based on long-term empirical observations and data describing ongoing developments, which provide insights for the likely development and outcome in the future. Recent trends allow us to understand developments we have had to deal with recently and to estimate their outcomes, as some of their consequences can already be observed today.

2. Trends with a prospective, uncertain character: they have a shorter history and are more uncertain as they might disappear without becoming established. They can be used to identify qualitative change, thus providing a more prospective view. This prospective character allows us to define and to analyze the field of uncertainty by identifying the main processes and their impact. The future impact can be estimated based on this, supported by expert surveys and interviews.

The paper builds on this, aiming to show how a basis for decisions could be created by using the concept of megatrends and describing the field of uncertainty based on prospective trends. Based on research done in the EU-FP7 funded project OPTIMISM, I) the main recent megatrends, as drivers of 
transformation in transportation, will be described, II) the field of uncertainty will be described based on prospective trends relevant in this field and III) potential risks, challenges and opportunities to be considered in decision-making will be identified.

\section{Recent megatrends shaping the future transportation system}

Megatrends describe fundamental, long-lasting processes which affect economy and society in multiple ways and thus also have an impact on supply and demand of mobility and transportation. Analyzing megatrends and their impact provides insights into the nature of the transformation process and related challenges. In the OPTIMISM project a literature review combined with knowledge provided by experts have identified megatrends as key factors affecting the transformation process of the transportation system. As the idea was to identify Megatrends considered as such by the economy and society rather than by academia, the list does not reflect academic discussion on megatrends and could be further extended. Most of the megatrends are interlinked and some of them include changes inside the transportation system which affect other parts of the system. Ongoing developments with a historical background of some decades and which can be supported by data, e.g. the increase in global population, rising share of Asian GDP or share of urban population, have been considered recent megatrends. Seven established trends have been distinguished in this category:

1. Globalization 2.0 describes a qualitative change in global economic growth, which will remain high in the coming decades with emerging economies experiencing higher rates [8]. The economic boom in BRIC (=Brazil, Russia, India, China) countries is leading to a global shift of economic and political power, prosperity and economic specialization and a "multi-polarization" of the world with international regulation gaps, e.g. concerning the internet. The worldwide redistribution of income affects demand for mobility services, vehicle purchases as well as the development of transportation technologies which will have to address needs from different cultural backgrounds as compared to the last few decades.

2. World population growth will continue and increase demand for goods, natural resources and energy. Together with a redistribution of prosperity, consumption in the emerging economies is rising, while in Europe, population is expected to decrease [8]. Rising prices, growing exploitation of natural resources as well as growing international trading and transportation are the consequences. The decrease in population in some European regions may lead to inefficient transport infrastructure, while urbanized areas have to tackle increasing traffic volumes.

3. Urbanization, the shift of population and economy to large cities, is strongest in emerging markets; even in Europe urbanization is expected to continue, although at a slower rate [8]. The concentration of people and labor markets in centers allows an increasing efficiency of transportation. Problems arise from the concentration of transportation during traffic peaks. The trends of centralization and the movement away from peripheries are leading to contradictory situations where the profitability, infrastructure and operations of transportation need to fulfill conflicting requirements. Enabling equality of accessibility and achieving true cost in transportation at the same time is one of the main challenges for the future.

4. Increase in inter-/intranational social disparities has taken place together with increasing wealth and income levels, intensifying prosperity gaps in the past few decades, especially in the emerging economies [26]. Prosperity gaps are accompanied by other social disparities such as access to employment markets, housing, education and health care - also in industrialized countries. Disparities in transportation are reflected in different or exclusive accessibility, depending on the pricing for mobility services, which may occur as side effects of political measures aiming to reduce traffic, emissions and the burden of public funding.

5. Demographic and social change in Europe will be reflected in the increasing share of the population over 65 expected in future, especially in the European Union [23], but also in the USA and Asia. Demographic aging will have a significant impact on mobility needs and services. As seniors nowadays, compared with previous generations, are healthier, wealthier and have a more active lifestyle, they travel more. Social changes such as decreasing household sizes influence the demand for housing, leading to new settlement structures and shifts in traffic. Changing lifestyles with more use of ICT and social media lead to behavioral changes and different mobility patterns and may also reduce physical mobility in general.

6. The upcoming knowledge society and economy is related to the structural change in the European economy from production to services and the shift within industries. The remaining branches of the production sector are oriented towards research and development and high-quality products based on a high level of education and know-how. Knowledge acquisition and innovation may lead to the development of green transportation technologies, multi-modal supporting ICT solutions and new mobility concepts. On the demand side, this could be accompanied by increased use of alternative transportation services like car- 
sharing, E-mobility or social-media-based and selforganized mobility.

7. Climate change, environmental pollution and environmental ethics have an impact as a global pressure issue that poses significant negative externalities on society. The costs of climate change through damage and necessary adaptation measures require new policies and decisions to meet the challenges and cover the costs. Environment-related political measures, such as taxes and regulations tackling emissions, are pushing technical development. When it comes to individuals, awareness of environmental issues is increasing [see 32]. If the economy reacts to this trend by creating corresponding products and services, behavioral change towards sustainable mobility and transportation could be achieved.

The megatrends described above have and will have an impact on transportation, not only affecting the system itself but also having severe consequences for policy and planning. The regional shift of demand and economic power as described in Globalization 2.0 is likely to cause a cultural shift of development and innovation in transportation, as solutions, technologies and infrastructure will be designed according to the needs of markets such as China, India and emerging countries. World population growth has already had effects, increasing pressure on resources in general, especially energy, and their price levels. This will lead to an intensified search for, and innovations in, substitutes. Increasing urbanization has already led to capacity overload in urban transportation systems. This will further increase and exacerbate the costs for infrastructure development and maintenance as well as the need to ensure safety, security and resilience in mass transportation. Disparities are not only reflected in the un/affordability of mobility for certain population groups, but also in the different accessibility and quality of transportation for urban and rural areas. Planning, infrastructure investment as well as the development of technology and mobility concepts focuses on cities. Rural areas are being left behind and becoming more and more peripheral. Demographic change is leading to seniorization, especially in Europe, the USA and China, which is increasing the mobility demand of a population group which not only has a more active lifestyle compared to previous generations, but is also, to a certain extent, physically limited. The ongoing development towards the knowledge society is reflected in implementation of ICT in transportation for information, route planning and ticketing which will further develop in the future, providing multimodal mobility. This enables individualized mobility based on public transportation and, on the other hand, creates a "knowledge \& information pressure" on users: a need to cope with new technologies, education and information seeking. Climate change will force the need to adapt the transportation system to changing weather conditions, supporting resilience as well as fighting the drivers, such as use of fossil energy and $\mathrm{CO}_{2}$ emissions. Innovation might be pushed, while increasing political and economic conflicts about responsibilities might also arise (Fig. 1).

\section{Prospective megatrends defining the field of uncertainty}

As recent megatrends provide some data-based evidence for future development, they allow for the creation of a vision of a likely future or, at least, likely future developments. Uncertainty exists due to the unknown dynamics of these megatrends, the unknown results of their interdependencies and less certain trends influencing the transformation process. Prospective, less established megatrends which have become apparent in recent years and are likely to have a future impact can be used to define the field of uncertainty - which means providing knowledge about relevant trends which should be taken into account when tackling future challenges, e.g. in political or planning decision-making. Prospective trends relevant for mobility and transportation have been identified: 1) shortage of energy resources, 2) technology change, and 3) crisis of mobility and (European) policy reaction.

\section{Shortage of energy resources}

The transportation sector is a major energy consumer, heavily dependent on fossil fuels and their price development. Scarcity of energy would not only affect transportation significantly; the role of transportation in energy consumption makes the sector one of the main starting points for changes when it comes to a transformation of the energy system and source. In 2010 , more than $25 \%$ worldwide and more than $30 \%$ of the final energy consumption in the EU was attributed to the transportation sector. In EU-28, the share of energy consumption in transportation has increased in the past 20 years. Road transportation consumes more than $80 \%$ of the energy in the transportation sector in the European Union and in the U.S. $[15,6]$. Due to the dynamic of demand for, and uncertainty of, fossil energy reservoirs, peak oil and the potential of substitutes like gas hydrate, scarcity remains a prospective trend. Although scarcity might not be reached in absolute terms in the near future, increasing prices create a relative scarcity in the sense of affordability. With rising energy demand, a steady growth in energy prices has been observed since the beginning of this millennium, with a peak in 2008, as reflected in the OECD statistics. In 2011, the end-use price for energy again rose to the peak level of 2008 [30]. Energy prices are especially difficult to handle due to their volatile character, which has also increased in the last few decades (Fig. 2).

Increasing demand for and use of energy related to economic and population growth have increased the exploitation of oil beyond the easily accessible reserves. This development 


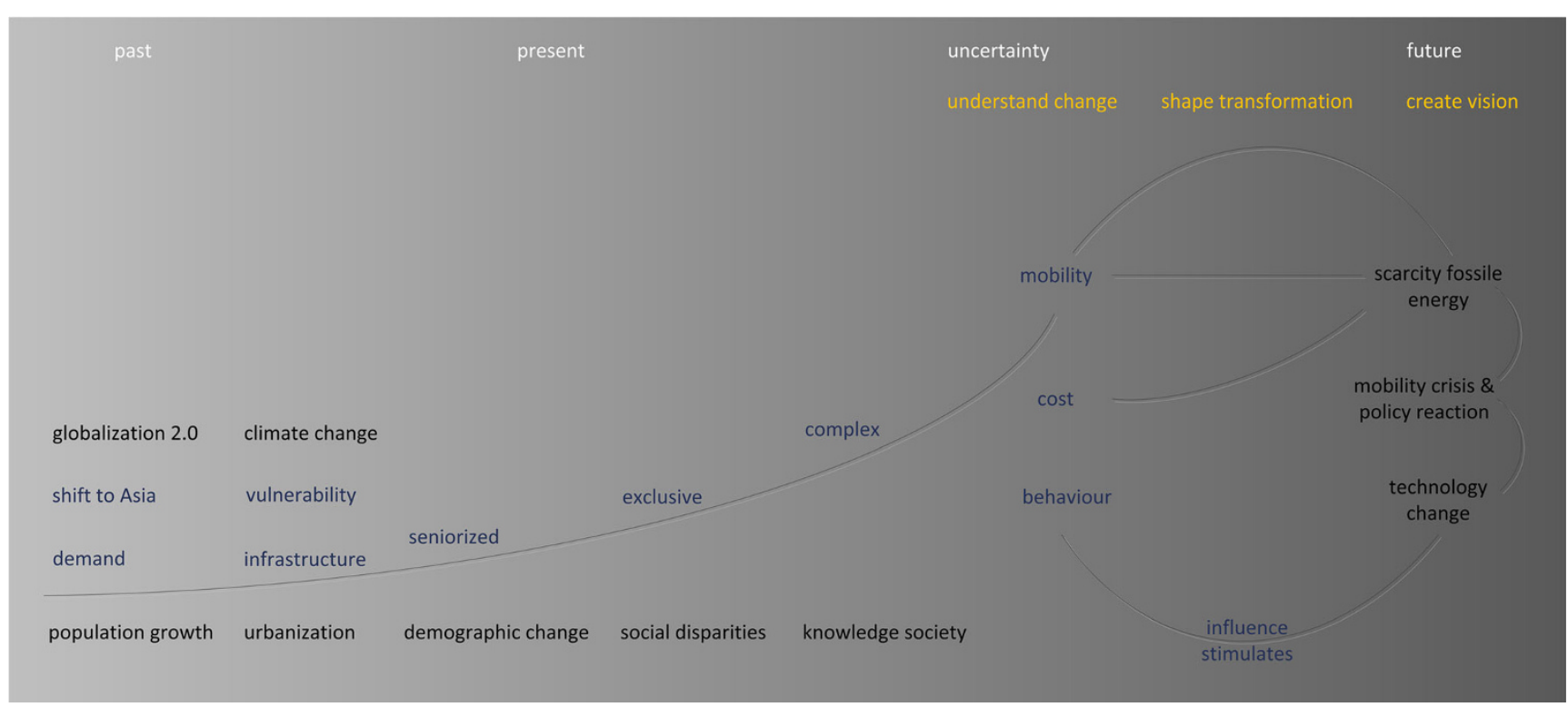

Fig. 1 Megatrends

is expected to continue, leading to complex, costly extraction and scarcity of resources [33]. The global energy consumption almost doubled from 4674 Mtoe (Million Tonnes of Oil Equivalent) in 1971 to 8918 Mtoe in 2011. While the total consumption increased, a shift between energy sources appeared. The share of oil as energy source decreased to $48 \%$, whereas natural gas made up $20 \%$ and electricity $22 \%$ of the total global energy consumption in 2011 [19]. China, India and Russia have significant shares of the overall crude petroleum consumption, but are not yet competing with the U.S. when it comes to total oil consumption. In addition, demand is shifting regionally. China, India and Brazil are leaders in terms of growing global oil consumption, while the crude oil consumption in emerging countries like Singapore, Vietnam and Saudi Arabia has also increased drastically [3]. Around one third of the oil consumption worldwide is in countries which have at least doubled their total since 1990. Countries which have increased their consumption by more than $30 \%$ in the last 20 years, which is the world average, are responsible for half of the world's oil demand. In other words, 30-50\% of today's oil consumption occurs in countries in Asia, Arabia and South America, which have increased their need for oil in the past 20 years considerably. This development is likely to continue at least for the next decades (Fig. 3).
Fig. 2 End-use energy price 1990-2013, index 2010 = 100 [30]

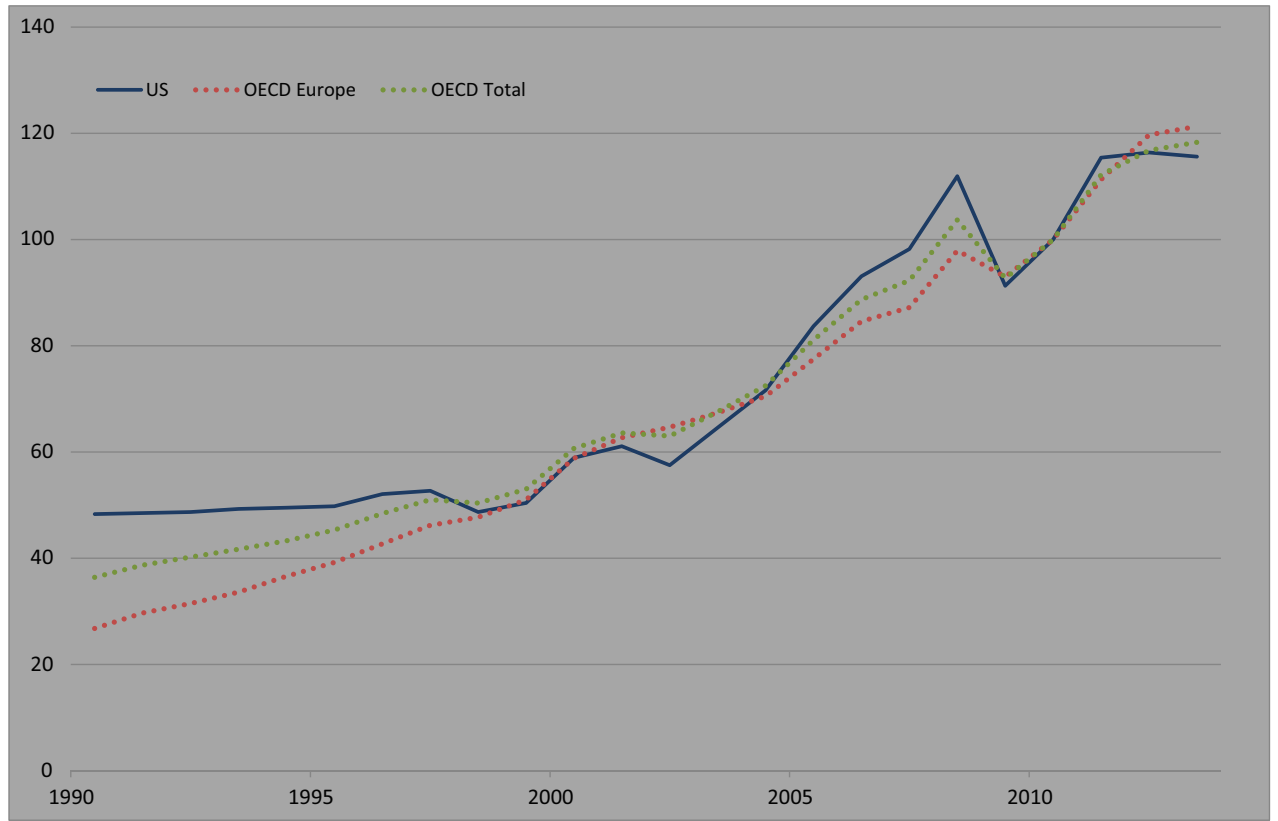


Fig. 3 Total petroleum consumption in selected regions, index $1995=100[18]$

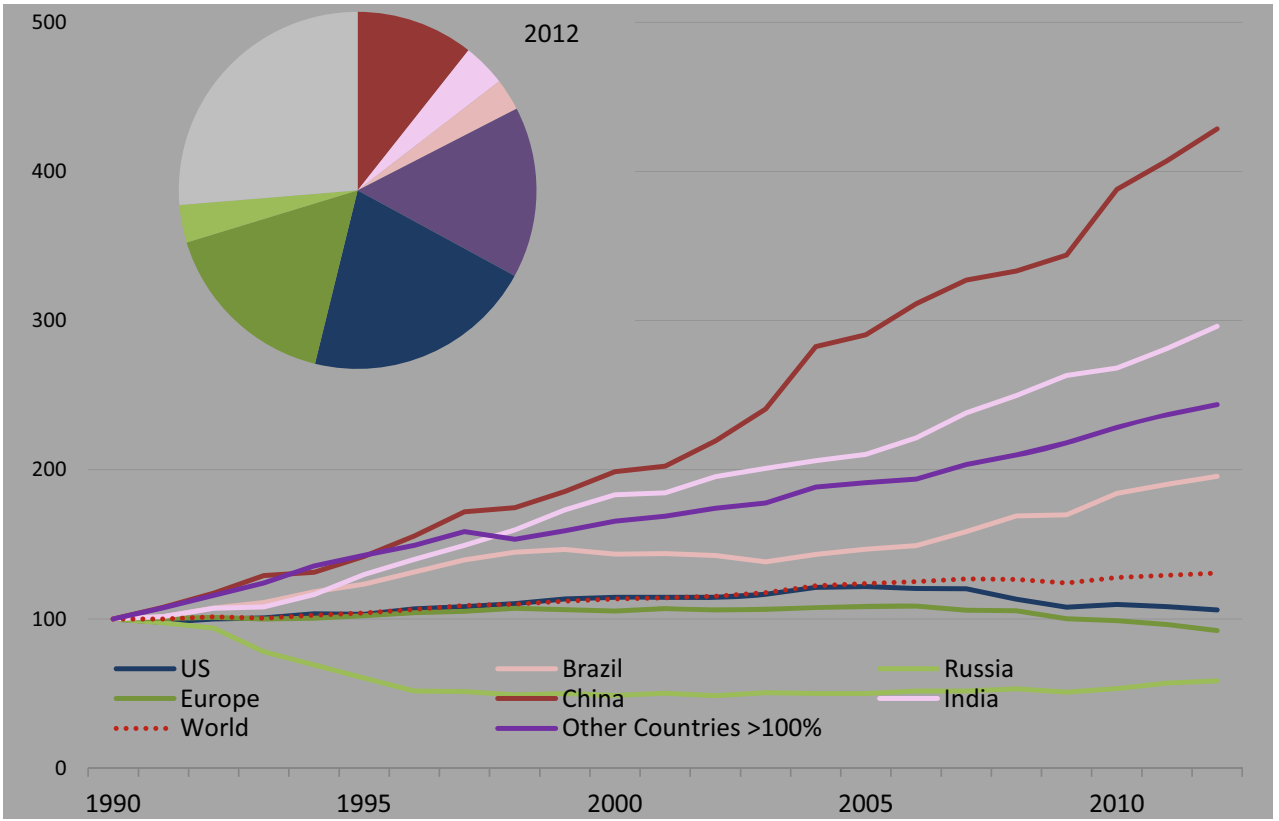

The consumption of natural gas is following a similar path to that of oil. It has had the fastest, steadily growing trend in China in the last few years and is expected to further increase, whereas the trend in other emerging markets has varied from year to year. Globally, the consumption has remained almost stable since 2007 due to the financial crisis. The U.S. consumes by far the largest amount of natural gas in absolute numbers, with a slightly stagnating or even decreasing trend of consumption for the last few years. Among emerging markets, Russia, China and Saudi Arabia have the highest consumption of natural gas [3].

When it comes to prognosis, differences in forecast studies reflect the uncertainty about the scarcity of energy. A study by the European Parliament's Committee on Industry, Research and Energy (ITRE) predicts peak oil, the maximum level of extraction and the moment when approximately half of the total oil reserves are used, to be reached between 2006 and 2026 [21]. The International Energy Agency predicted peak oil to have been in the year 2000 , but at the same time presented varying, long-term prognoses for oil fields to be developed and discovered in the future. According to some of the prognoses, oil reserves would not start declining before 2030 [20]. Another forecast for fossil fuel reserves based on historical data and versatile scenarios estimated the peak for oil extraction to be in the year 2015, the time horizon for maximum extraction of natural gas in 2035 and for coal in 2052 [24].

Besides the question of if and when physical or relative scarcity of energy will occur, policy-makers have already started to address the issue in their agenda. As the economy and society - especially the field of transportation and mobility - are heavily dependent on energy availability, national policies reflect the situation in the different strategies they adopt to cope with the problem, with the aim of becoming more energy autarkic. Depending on available resources, situation and strategies differ on a national basis. While China is investing abroad, e.g. in Africa, in order to extract raw materials and other resources, the United States increasingly relies on the resources in its own country. Driven by a combination of advances in drilling and new technologies, the USA is aiming to become completely self-sufficient in the energy market. In the European Union, versatile political ideas and approaches of the individual member states as well as existing bilateral agreements with suppliers of raw materials (e.g. German-Russian gas pipeline agreement, LNG contracts between Spain/France and Algeria) lead to different strategies, which have to be considered when harmonizing the EU's energy policy.

Increasing demand and prices for natural energy resources are inevitable following a historical path of economic-growth-related consumption. Uncertainty comes from volatility related to disruptive events such as political conflicts or economic crises - as well as due to the uncertainty of accessible deposits and substitutes for fossil energy. The nature and direction of change towards the use of fossil energy alternatives remain as unclear as the speed of adaptation of the transportation system with its infrastructure, vehicles and other components.

Technology change

Historically, technology has been seen as both, a driver of change, e.g. in technological utopias, and a solution to recent or future problems. Although the discussion remains 
inconclusive, it is beyond doubt that technological development is crucial for change or transformation. The automobile, personal computer or ICT are prominent examples of technologies not only changing lifestyle, but society and economy in terms of structure, organization and processes. The impact of key technologies is difficult to predict. Thus, technological change is characterized as a prospective megatrend due to the unpredictable impacts on transportation and mobility. Fields of technology which are changing most dynamically and are expected to continue to do so in the future will particularly affect the transformation of transportation.

Technology leaps are expected especially in nanotechnology, biotechnology and information and communication technology - also affecting transportation and mobility. Unlike technical developments, this might lead to a paradigm shift, as nanotechnology provides opportunities in the fields of medicine, electrical engineering and material technology. The comprehensive nature of this technical shift makes it difficult to predict its impacts. Technological progress in specific fields has impacts outside their boundaries and can create synergies [27]. Light materials, new battery technology or ICT solutions for intelligent transportation organization could support energy-efficient mobility solutions. Through these synergies, new approaches and ways of thinking are created. The consequences are and will be revolutionary and can be compared with industrialization or digitization. Behavior has already gone through a fundamental change due to the internet, smartphones and social media services. The ongoing digitization of everyday life, ambient intelligence, affects the economy and society by changing working environments, living habits and consumer behavior. The implementation and use of new technologies could lead to a paradigm shift which enables new ways of life, working methods and the organization of mobility.

In transportation, innovation is expected to change vehicle, material and engine technologies as well as infrastructure technologies. To identify the main fields of change and to characterize the change, technologies which might achieve a breakthrough have to be identified and analyzed in terms of their impact on the transportation system and their potential to shape the transformation process. Thus, based on literature, research technologies related to transportation have been categorized and fields for future innovation have been identified [16] (Fig. 4).

Based on these, European transportation experts from research, industry, policy and planning have been asked to estimate the influence by 2050 of identified selected technologies in vehicles (autonomous vehicles, high speed trains, compressed air cars), engines (electric, efficient fossil, fuel cell, hybrid), material and infrastructure technologies (vehicle-to- vehicle/infrastructure communication, intelligent roads, traffic control systems). Besides this, the experts were asked an open question about additional technologies of importance for the future. The respondents identified autonomous vehicles despite the fact that only prototypes exist so far. Driver assistance systems based on similar sensors and applications to those of autonomous vehicles are already available and might support the marketability of autonomous driving. Besides this, high speed trains, as vehicle technologies with the strongest influence by 2050, were mentioned; their potential can be explained as they provide alternatives to flying and allow travel times in train transportation to be shortened [16] (Fig. 5).

Electric, hybrid and fuel cell engines were acknowledged as essential engine technologies with major importance for future transportation by more than half of the experts. When it comes to electric vehicles, the range of the batteries is expected to extend considerably and the costs are expected to decrease due to established technologies. Hybrid vehicles are already established and combine the practical, positive sides of conventional and electric vehicles, leading to reduced fuel consumption and lower direct emissions due to electricity use. More generally, fuel efficiency was regarded as an aspect with a positive influence on future vehicles [16].

Lightweight construction was identified as the most relevant material technology for both public and private transportation modes. Innovative materials can reduce a vehicle's weight and further contribute to lower energy use and, through that, to lower emissions. Vehicle-to-vehicle and vehicle-toinfrastructure communication as well as intelligent roads and traffic control systems were seen as ICT and infrastructure solutions with a substantial impact in the future [16]. The use of ICT and smart transportation systems were identified in the survey as solutions with a great influence on future transportation in terms of their potential to optimize, control and improve the transportation systems and lead to convenient, multimodal, more efficient and safer transportation services.

As additional and innovative technologies with a long-term effect on the transportation sector, more futuristic, emerging solutions were identified. For example, road-to-vehicle energy harvesting, bio mimicry as an imitation of natural phenomena to solve complex problems through technology, open rotor engines and robotic cars were mentioned as potential future technologies.

In summary, experts see high market potential for technologies leading to higher "autonomy" of the vehicle - which suggests a kind of hyper-individualization of transport on the individual level. In fact, autonomous driving relies on advanced driving control systems to ensure safety and security. Experts also focus on the transition to a flexible IT-based system as well as on increasing material and resource 


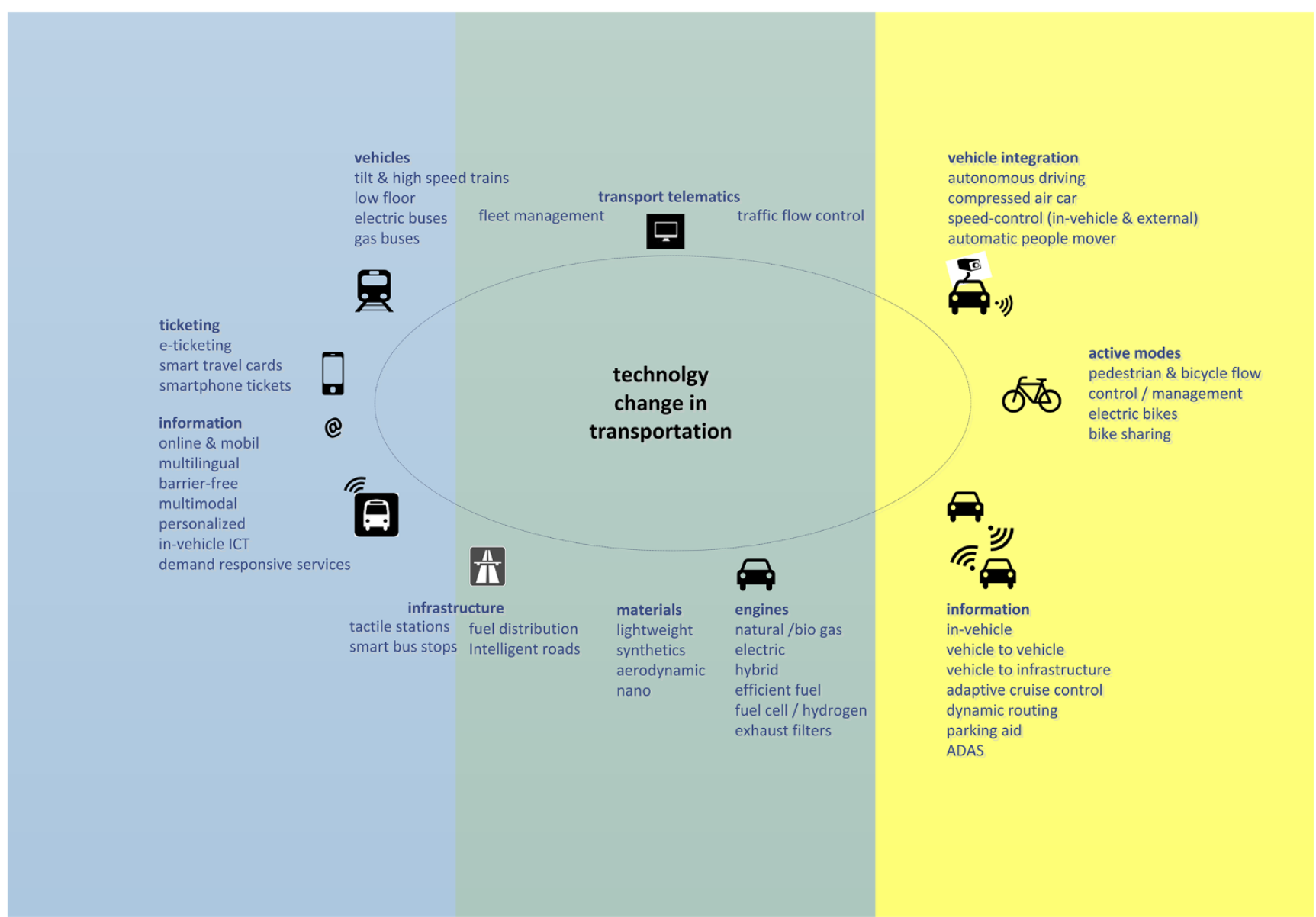

Fig. 4 Technology fields related to public and private transportation

efficiency in transportation; this includes more efficient engine technologies and substitutes which might attract more people to individual transportation. As a consequence of these perspectives, the system would gain complexity and involve more individual users, increasing the need for communication, technologies and resources in the end.
Fig. 5 Influence of technology by 2050 : experts' rating

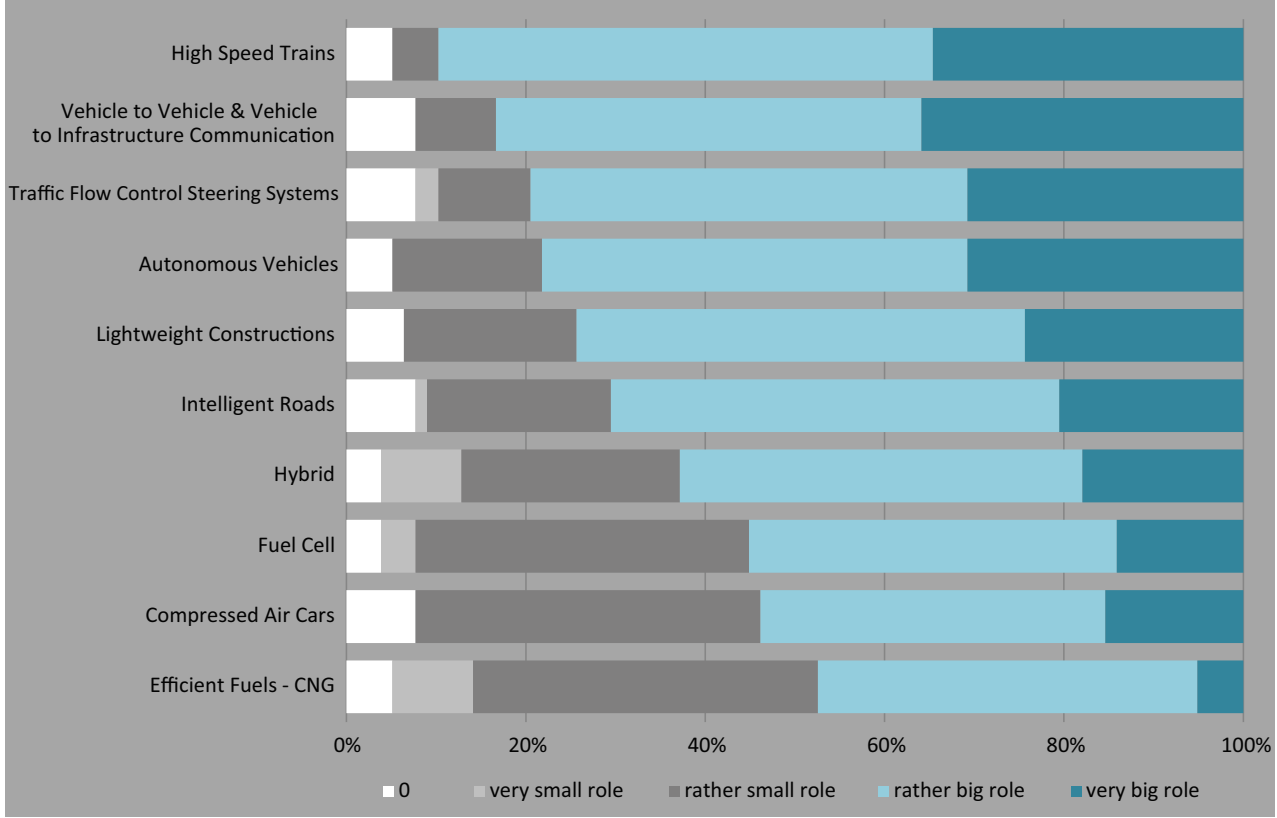


Crisis of mobility and policy reaction in Europe, the US and China

The world is shaped by a growing global economy and rapid spatial developments, leading to increasing demand for mobility and logistics as described earlier.

Urban density and spatial organization are crucial elements influencing energy consumption, especially in transportation and building systems. With increasing wealth, households choose larger living spaces, leading to urban sprawl, suband peri-urbanization. These structures, and thus the backbone of our society and economy, rely on an extensive transportation infrastructure which has developed over many decades. Due to this and to avoid sunk costs of previous investments in this infrastructure, there is a strong motivation to continue the current system rather than to redesign and redirect development. A challenge related to this is that since a significant amount of time and money is needed to maintain the overloaded infrastructure and to design a new one, only limited human and financial resources remain for planning and developing alternative mobility systems [37]. A decision for one strategy, an investment in certain infrastructure, is, at the same time, a decision against alternatives. Thus, dealing with the crisis and adapting successfully to transformation is a matter of strategy, priorities and decision-making - aiming to allocate resources appropriately to solve problems in the long term.

Continuing along the previous path, costs for infrastructure are expected to further increase, as an IEA model calculation estimates. According to the model, in 2050 both road and rail transportation network length will increase by $60 \%$ compared to 2010 levels, while construction costs will represent $0.7 \%$ of global GDP, and including reconstruction, upgrade, annual operation and maintenance costs, transportation spending may be $2 \%$ of GDP [7]. While cities and agglomerations gain centrality and infrastructure, the accessibility of rural areas has started to decrease regionally, compared to cities and also in absolute terms. Some municipalities are hardly accessible by public transportation. Non-motorized, elderly and mobilityimpaired persons have difficulty accessing healthcare or services for daily life - disparities between urban and rural areas as well as between different social groups occur. As mobility is a basic need for the national economy as well as for the individual, unaffordability of mobility causes an exclusion on the side of the individual and compromises economic wealth.

Besides the increasing consumption described above, prices of energy resources and infrastructure, and emissions caused by transportation are the main problems. Emissions from transportation create unacceptable health conditions according to numerous medical investigations [22]. Cities in China, in particular, have to deal with dense smog, which leads to serious health concerns. Important in this regard are the cities of Beijing and Shanghai, and the Pearl River Delta region, including Guangzhou, Shenzhen and Hong Kong [4].
The situation is likely to worsen as the number of road vehicles in China might increase fourfold in 2010 to as much as eightfold in 2030 [40]. According to the International Energy Agency (IEA), in a scenario "in which fuel economy standards are tightened and a small uptake of advanced vehicle technologies is present, transportation energy consumption and emissions are projected to increase by nearly $40 \%$ by 2050".

The consequences and side effects of growing transportation and mobility described above can lead to a crisis when congestion, emissions and cost exceed manageable dimensions. The term 'mobility crisis' was chosen to describe a period characterized by increasing problems requiring adjustments and change. During this time, new concepts, financing models and political actions are required to adapt to the changing environment. Today's policies and investments point towards a vision of the future, due to their long-term outcomes. The increasing pressure due to limited natural and financial resources is reflected in several political strategies. Countries differ in their national targets and strategies. In particular, the strategies of big consumer countries and those with high growth rates of consumption will be the trendsetters of global supply and demand in energy. Thus the political strategies of the EU, China or the USA are crucial; although they are large fossil energy consumers, they are pursuing ambitious industrial strategies in solar, wind and nuclear markets which will have a strong impact. One approach to addressing the problem is the concept of sustainability.

The European Union has created a concept for Sustainable Urban Transportation Plans, which covers not only environmental impacts of transportation, but also competitiveness and social aspects [36]. The integration of transportation and spatial planning was identified as one key factor to increase sustainability in transportation $[11,12]$. In the case of roads and railways, this is reflected by the TEN-T (Trans-European Transport Networks) projects with an investment of over $€ 7.2$ billion in 327 projects from 2007 to 2013, covering different transportation modes. Thus, the EU strategy also covers the field of energy. As the world's largest energy importer, the European Union is likely to be more vulnerable to supply risks [10]. In 2007, EU imports were about $50 \%$ of its energy needs, and approximately half of its energy was imported from Russia in the form of oil and natural gas [1]. The European Union's energy strategy is one of replacing the import of fossil fuels with renewables in order to strengthen economic competitiveness.

Therefore the EU energy strategy for 2020 focuses on energy efficiency with a pan-European integrated energy market. Energy technology and innovation are key issues to achieve the Green Paper's targets by 2020: a GHG emission reduction of $20 \%$ relative to emissions in 1990 and a share of renewable sources of $20 \%$ [13]. 
In China's energy strategy till the'90s, the key objectives were self-reliance and self-sufficiency. But China's demand for energy at the beginning of the' 90 s changed the strategy, as the domestic oil production could not meet the demand and enterprises started to seek oil in foreign markets [41]. With around one eighth of today's global energy consumption and growth rates of more than $400 \%$ between 1990 and 2010, China's strategy will shape the future of the world energy market fundamentally. The 11th Five-Year Plan 2006-2010 prioritized expanding and securing domestic energy supplies in China - but also, for the first time, energy conservation through economic efficiency, reduction of poverty and environmental preservation were put on the agenda.

Besides the plan to increase renewable energy to up to $15 \%$ of the total by 2020 - compared to $9.5 \%$ in 2008 [35] - 'The Twelfth Five-Year Plan for National Economic and Social Development' mentions concrete goals for decreasing energy consumption and $\mathrm{CO}_{2}$ emissions: '... increase the ratio of non-fossil energy to primary energy consumption to $11.4 \%$, reduce the energy consumption per unit of GDP by $16 \%$, reduce the carbon dioxide emission per unit of GDP by $17 \% \ldots$ ' [29 p 13]. The 'Transformation of Energy Production and Utilization' is part of the plan: 'We will also develop nuclear power on the basis of ensuring safety, strengthen the construction of projects that support grid integration, and develop wind power effectively, actively develop other renewable energy sources such as solar energy, biomass energy, and geothermal energy, and boost the popularization and application of distributed energy resource systems' [29 p 30].

Besides this, up to now great efforts have been made in financial outward foreign direct investments (OFDI). The global financial crisis and turmoil in many parts of the Middle East and Northern Africa forced China to diversify energy sources to reduce the risk of oil shortage or unavailability. Therefore several investments in the production of fossil fuels overseas were made.

China has a high potential for increasing renewable energy if the long-term strategy supports such energy sources. This would also force technological development and push renewables worldwide. Cooperation between government and industry with regard to investments in science and technology in the energy sector has given China global leadership in clean energy. Fighting climate change and forcing renewable energy are positioned strategically in China's energy structure. Forecasts suggest that the share of renewables in the country's overall energy mix could reach $28-32 \%$ by 2030 and 30 $45 \%$ by 2050 [25].

The USA's energy strategy was historically characterized by the import of energy. After the USA oil production peaked in 1970, their production declined more and more and the imports of fossil fuels increased. But efforts made in hydraulic fracking changed the situation. The United States is projected to become the largest global oil producer by around 2020 overtaking Saudi Arabia by the mid-2020s [14]. Although the 'Energy Independence and Security Act 2007' describes energy reduction goals and goals to increase renewables, steps and implementation remain unclear and nonbinding [17]. Energy production in the US is driven by the market. The possibility of producing fossil energy using hydraulic fracking currently has priority over other efforts and will probably extend the fossil age, postponing the tipping point towards a change to renewable energy use in the US, and also having a global impact.

There are alternatives to the fossil fuel-based energy generation in the US. Primarily hydropower, but also solar photovoltaic and wind-power have experienced an increase over the last decade. The National Renewable Energy Laboratory confirmed that renewable energy could cover $80 \%$ of USA electricity demand by 2050 [38].

Part of, and related to, the energy strategy is energy taxation, which affects the national price levels, provides state income and limits or forces consumption. Tax rates differ between countries. The US forced high consumption with low taxation, leading to a transportation system with infrastructure, technologies, decisions, habits and behavior based on cheap oil. Compared to the US, taxation rates are higher in Europe, although they differ within the European Union. In general, compared to other OECD countries overseas, tax rates are high in European Union countries, while Canada, the US and Mexico have low tax rates on liquid fuels. Besides the contribution of oil taxes to public finance, they are crucial for the national economy. While the economic structure, society and the transportation system in the US evolved based on cheap, lowtaxed oil, higher prices due to taxes have led to relatively higher energy efficiency in other countries - which would make a transformation process even more difficult for the US compared to Europe. On the other hand, higher tax rates would allow countries to politically buffer times of high oil price volatility by lowering taxes to avoid damage of the national economy (Fig. 6).

\section{Future transformation or adapting systems from the past?}

The work described in this paper aims to expand knowledge of the ongoing change process in the transportation system as well as to estimate the likely future development and outcomes - based on a qualitative analysis of recent, established and prospective, uncertain megatrends. Knowledge and awareness of the characteristics of the change process should enable decision-makers to actively shape development according to the goals they have set as a process of transformation of the transportation system. To draw a picture of the 


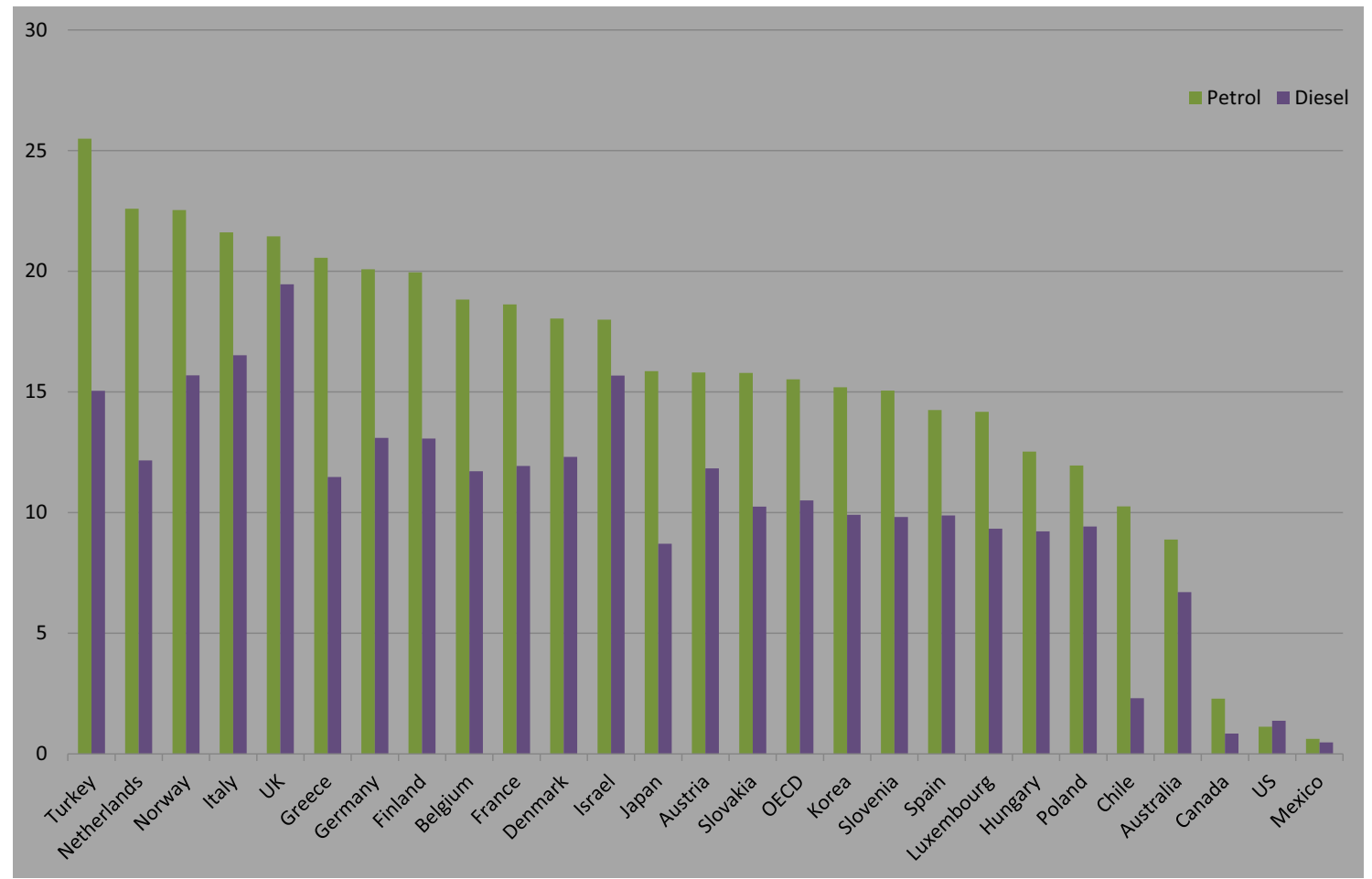

Fig. 6 Effective tax rates (€/Gigajoule) on petrol and diesel fuels in selected OECD countries in 2013 [31]

future, recent megatrends were used to describe solid, likely developments, while prospective ones allowed us to estimate developments which are more uncertain.

Recent megatrends turned out to be « trends of increase », leading to a more global, urban and older population resulting in more mobility and higher transportation volumes. Social and regional disparities are also expected to increase, as well as the supply of knowledge-based products and services which require knowledge and skills to use and which might therefore open up or deepen the gap between social groups according to their capabilities. Beside this, « trends of change » can be identified. These include climate change, with unpredictable extreme weather events and unknown, regionally distinct effects, as well as the shift of economic and political power towards Asia, which will channel a part of the described increase in mobility demand to Asia's urban and metropolitan areas. In generalized terms, concerning transportation and mobility, the world of tomorrow based on the analysis of the megatrends as described will be more:

- crowded: demand for mobility for more and older people, especially in cities and in Asia, will further increase,

- complex: more sophisticated products and services will be provided, requiring skills and learning to use them,

- exclusive: the gap between social groups will widen with regard to if and how often and on which level of quality they might be able to afford mobility and thus to take advantage of opportunities for their lives and individualization,
- vulnerable: extreme weather events related to climate change will affect the transportation system more often in as yet unpredictable dimensions, while due to increasing complexity and IC and other technology use, the system will become more vulnerable,

- diversity-driven: related to the shift of economic growth and mobility demand towards Asia, future mobility on a global scale will be shaped based on cultural and political mindsets that are different from today.

The three prospective trends identified are connected to and partially dependent on the recent megatrends, with their consequences of a more crowded, complex, exclusive, vulnerable and diversity-driven world of mobility.

It is clear that due to growing mobility demand and transportation, fossil energy resources will be further exploited, which will lead to scarcity, reflected in increasing prices and, in the end, in limited availability; what remains unclear is the timeline of the development. Megatrends of increase will accelerate the speed towards scarcity - supported by the shift towards Asian growing economies, which are still hungry for more mobility and car use. In contrast, exclusivity and social and income disparities might serve as a modulator for this increase.

Increasing demand, if it causes shortages and scarcity of energy, as well as the related emissions are aspects leading to a crisis and resulting in political reactions to try to tackle the related problems. Today's political strategies affect the next 
decades due to their long-term investments in the transportation and energy system, which are persistent in view of the fact that infrastructure, vehicles, etc. take decades to redesign.

In particular, Europe's, China's and the USA's strategies on energy resources are crucial as these three regions accounted for more than $75 \%$ of the world's energy use in 2012 - with further increasing dynamic of consumption in China and, on a lower level, also in the US. Fossil stabilization seems to be the mainstream of their strategies on the supply side. Securing oil supply by autarky and/or diversifying the supplying countries are especially obvious in the US and Chinese strategies although China seems to follow a hybrid strategy, investing in fossil energy security combined with an increase in renewables. A few European countries are also developing strategies of change towards renewable energies, especially Denmark and Germany. As today's investment in infrastructure, technologies and related industries set the path for the next decades, today's strategies on the energy supply side not only support but enforce the fossil path. Instead of addressing the threat of absolute scarcity of global fossil energy resources in time, national strategies focus on securing their own access to remaining resources. Competition on a national level seems to lead strategies more than the global finiteness and availability of fossil energy.

Besides this demand side, policy is important for shaping the development in, and the future of, transportation. Moving from liquid fossil fuel to renewable energies would mean replacing around a billion cars - with 250 million in the European Union [13,39], as well as vehicle and infrastructure production, reorganization and related logistics. This would take decades. Up to now, there have been minor efforts compared to the investments made to run the fossil-fueled world.
No substantial change can be expected for the next 20 to 30 years. An exception is China's policy on electric vehicles, mainly motivated by tackling urban smog problems, which has the potential to stimulate technology development in Europe and the US too. This could create impulses for a change as long as it is combined with non-fossil energy production (Fig. 7).

Directions and consequences of technology change are difficult to predict. They are driven by the market, economy and society - as well as being related and reacting to political regulations and conditions. To address the challenges coming with increasing mobility and scarcity of fossil energy, innovation to reduce energy consumption and $\mathrm{CO}_{2}$ emissions, such as engines or lightweight vehicles, are needed as well as solutions for mass transportation. When asked about the future importance of a selected range of technologies, experts saw more potential in technologies enabling new products or services or more speed in the case of high-speed trains. Communication, autonomization and traffic control systems provide new options which seem to be more promising than technologies addressing problems, especially economization. This might be due to the assumption of marketability. Without pressure of prices or regulations, no need to buy or sell energy-efficient technologies arises - as shown in the past: e.g. before more efficient fuel engines were introduced in response to $\mathrm{EU} \mathrm{CO}_{2}$ emission limits, consumers did not buy smaller cars and car manufacturers did not sell notable numbers of them. Technology change seems to be driven 1) if innovation promises new opportunities for producers to sell or for customers to buy or 2) as a reaction to regulations, price shock etc.. It is likely that experts not only estimate the importance of economizing technologies to be low, but also
Fig. 7 Trends for vehicle ownership in selected regions [39]

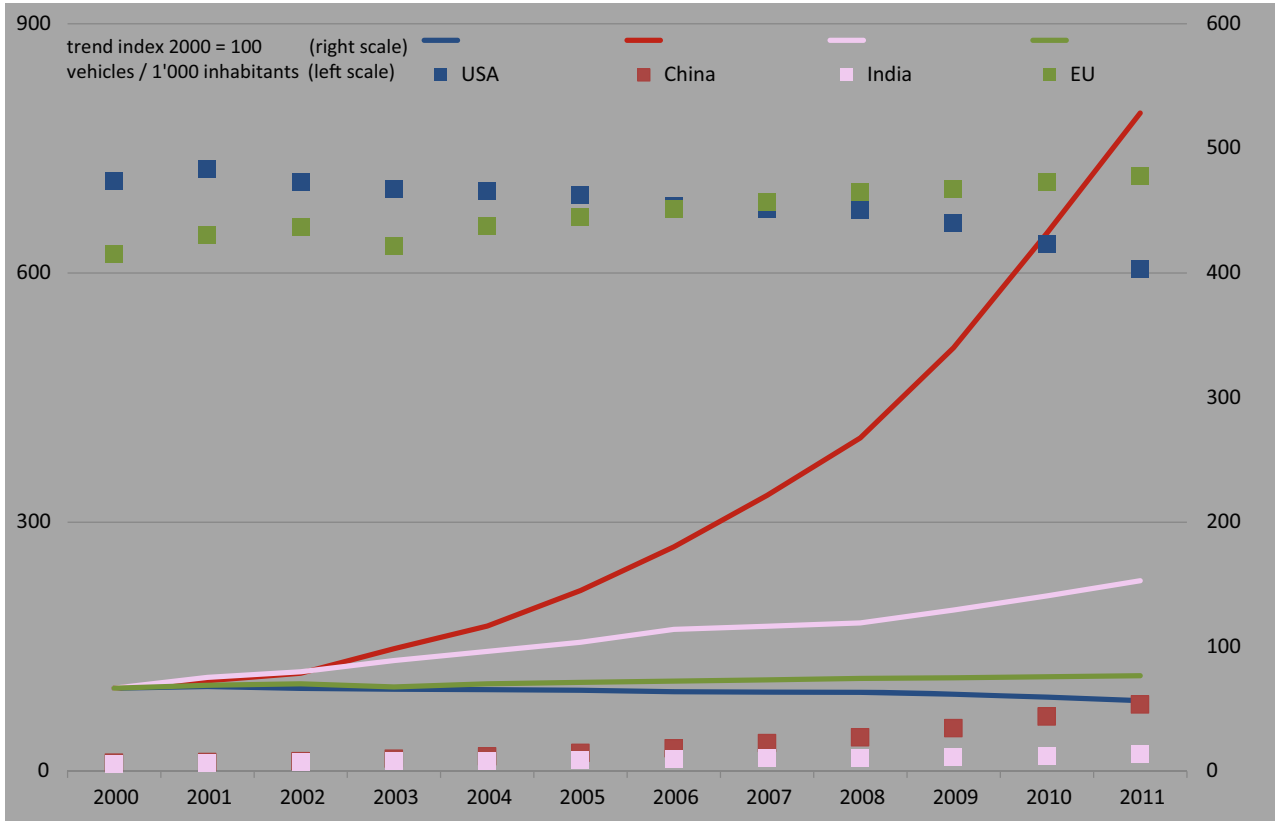


make their decisions based on this mindset. Scarcity of fossil energy seems to be an almost logical consequence: this goes along with the growth of mobility, which is driven by the trend to individualize in the sense of taking more opportunities for life optimization.

Political regulation is able to interfere with this « natural » growth cycle; regulations and subsidies can serve as game changers. So, how does policy deal with transportation and energy? First of all, decision-makers are representatives of society and the economy; they cannot go too far ahead of the parade - unless they are extremely visionary and selfconfident leaders.

A tipping point can only be reached if large markets are subject to the same regulations or political conditions, which would need to diverge significantly from fossil-fueled transportation strategies. Such a real transformation can hardly be imagined without a paradigm shift: from 'reinvesting' gains in efficiency for higher performance towards energy savings, integration of renewables and redesign of transportation and energy supply. At best, we might be at the very beginning of such a paradigm shift. In China and Europe, promising signs can be identified in the demand side strategies for transportation, and these might stimulate technological development towards change. However, they need to be linked to an energy policy that supports renewables.

The analysis of megatrends showed how strongly the future development of transportation is determined by traditional drivers: growth and increasing use of finite resources, regardless of the fact that this heads towards a fossil-fuel and overload crisis in transportation. Transformation needs new forms of mobility based on old infrastructure and a restructuring of the given infrastructure parallel to continuously developing the traditional system into a future resilient one. One of the main findings of the work underlying this paper is that astonishingly few political strategies seem to tackle the high risk of the one-way fossil system and the obvious threat of scarcity. At the moment, the mainstream of the change in transportation appears rather as a substitution within the boundaries of the fossil-fueled world than as transformation in the sense of a fundamental change.

A barrier for transformation and for a paradigm shift addressing the signs of the crisis is the inertia of the given system, with a fixed infrastructure providing high mobility at least in some parts of the world based on a high car ownership rate. Relative scarcity of energy as reflected in high and volatile prices, as well as absolute scarcity with non-availability, seems to be unavoidable. From a European and western world perspective, one might think we are already dealing with the challenge and will be capable of doing so in the future. What will be different from today is that the future market will show a power distribution concerning consumption and demand, and concerning basic and raw materials, which is different from today. Thus, dealing with new competitive situations and adapting to a changed world of dependencies will be one of the key factors.

Besides challenges coming from this side, opportunities might also arise. While the thinking dominated by the US and the western world has not succeeded in leaving the problematic fossil energy path, impulses for change may arise from China, other Asian countries and Europe. Besides powerful political strategies and large investments, social trends, which are underestimated with regard to their influence and speed, also have the potential to change the world of transportation. Not only monitoring bottom-up changes in acceptance and use of technologies, but also directing behavior by incentives, nudges and regulations can have a serious impact.

To develop an alternative path of development would require creating an idea of transformation as a process of actively shaping and redirecting the system development by anticipating and addressing future challenges - instead of competing for remaining fossil resources and sinking investments in out-dated strategies.

Using megatrends with their classification of recent, established and prospective, uncertain trends provided a helpful basis for the qualitative analysis of shaping frame conditions and estimation of their future relevance. Although starting points for action could be identified, more in-depth analysis and integration of quantitative data would be needed to provide more evidence. Further research could combine the approach with scenario building and additional expert surveys to both, broaden the context perspective and provide a more detailed analysis of potential future developments, impact and interaction of different trends.

Acknowledgments We especially have to thank Paul Kelly for his helpful support and constructive feedback.

Open Access This article is distributed under the terms of the Creative Commons Attribution License which permits any use, distribution, and reproduction in any medium, provided the original author(s) and the source are credited.

\section{References}

1. Belkin P (2008) The European Union's energy security challenges. CRS Report for Congress. Library of Congress, New York

2. Brög W et al (2005) Societal megatrends. Like it or not, the framework is set. Transportation is also embedded in this changing world and efforts have been allocated to envisage its development, 56th UITP World Congress. 
3. Central Statistics Office (2013) Energy statistics 2013. Central Statistics Office, National Statistical Organisation and the Ministry of Statistics and Programme Implementation, Government of India

4. Chan CK, Yao X (2008) Air pollution in mega cities in China. Atmos Environ 42:1-42

5. Delle Site P, Salucci, MV, Hoppe M, Seppänen TM, Christ A, Arsenio E, van Grinsven A, Morris D, Anoyrkati E, Brooks R, Hepting M, Kompil M, Tavlaki E, Micharikopoulos D, Akkermans L (2012) List of potential megatrends influencing transport system and mobility behaviour. In: OPTIMISM. Optimising passenger transport information to materialize insights for sustainable mobility. Brüssel: European Commission

6. Davis SC, Diegel SW, Boundy RG (2013) Transportation energy data book. Edition 31. Center for transportation analysis \& energy and transportation science division. Vehicle technologies program, Office of Energy Efficiency and Renewable Energy and the U.S. Department of Energy

7. Dulac J (2013) Global land transport infrastructure requirements. Estimating road and railway infrastructure capacity and costs to 2050, International Energy Agency

8. European Environmental Agency EEA (2011) The European environment - state and outlook 2010: assessment of global megatrends. EEA, Copenhagen (CTL_T 3)

9. Economides SB et al $(201 \overline{2})$ Paradigm shift for future mobility: a cross country analysis of behavioural policies. Procedia Soc Behav Sci 48:2588-2596

10. EC European Commission (2010) Analysis of options to move beyond $20 \%$ greenhouse gas emission reductions and assessing the risk of carbon leakage COM (2010) 265 final, Brussels

11. EC European Commission (2011) WHITE PAPER roadmap to a single European transport area towards a competitive and resource efficient transport system. COM (2011) 144 final, Brussels

12. EC European Commission (2011b) IMPACT ASSESSMENT accompanying document to the WHITE PAPER roadmap to a single European transport area - towards a competitive and resource efficient transport system. SEC(2011) 358 final, Brussels

13. EC European Commission (2013) GREEN PAPER - a 2030 framework for climate and energy policies. COM(2013) 169 final, Brussels

14. Energy Security Leadership Council (2012) A national strategy for energy security - Harnessing American resources and innovation. Edited: Energy Security Leadership Council. 134 p., Washington D.C.

15. Eurostat (2013) Eurostat - energy, transport and environment indicators 2013. Eurostat Publications

16. Hoppe M, Christ A, Seppänen TM, Winter M et al. (2013) Recommendations on the principles of sustainable mobility. In: OPTIMISM. Optimising Passenger transport information to materialize insights for sustainable mobility. Edited: European Commission, Brussels

17. House of Representatives (2007) Energy security act. One Hundred Tenth Congress of the United States of America. Washington

18. IEA (2014) Energy consumption statistics. International Energy Agency. Retrieved April 20th, 2014, from: http://www.iea.org/

19. IEA (2013) Key world energy statistics. International energy agency

20. IEA (2008) World energy outlook 2008. International Energy Agency, Paris
21. ITRE (2009) Eco-innovation - putting the EU on the path to a resource and energy efficient economy, Part 1. Requested by the European Parliament's committee on Industry, research and energy. Conducted by the Wuppertal Institute of Climate, Environment and Energy, Factor 10 Institute and SERI Nachhaltigkeitsforschung und Kommunikations $\mathrm{GmbH}$

22. Krzyzanowski M et al. (2005) Health effects of transport-related air pollution, World health organisation

23. Lisiankova K, Wright RE (2005) Demographic change and the European Union labour market. Natl Inst Econ Rev 194(1):74-81

24. Maggio G, Cacciola G (2012) When will oil, natural gas and coal peak? Fuel 98:111-123

25. Mastny L (2010) Renewable energy and energy efficiency in China: current status and prospects for 2020. Worldwatch report 182. Edited: Worldwatch Institute. Danvers

26. Mici PE (2007) Das ZukunftsRadar. Die wichtigsten Trends, Technologien und Themen für die Zukunft. Megatrend. Offenbach

27. MIT Massachusetts Institute of Technology (2011) The third revolution: the convergence of the life sciences, physical sciences, and engineering

28. Naisbitt J (1982) Megatrends. Warner, New York

29. National People's Congress (2011) Resolution of the national people's congress on the outline of the twelfth five-year plan for national economic and social development

30. OECD (2013) Consumer prices - energy. OECD StatExtracts, prices and price indices - consumer prices. Retrieved February 20th, 2014, from: http://stats.oecd.org/index.aspx?queryid=221\#

31. OECD (2013) Taxing energy use: a graphical analysis. OECD Publishing, Paris

32. OECD (2008) OECD environmental outlook to 2030. OECD Publications, Paris

33. Schoffield H (2014) Paris car ban imposed after pollution hits high. BBC Europe. Retrieved April 30th 2014 from: http://www.bbc.com/ news/world-europe-26599010

34. The World Bank (2010) Cities and climate change: an urgent Agenda. Edited: The International Bank for Reconstruction and Development/The World Bank. Washington D.C.

35. The European Parliament (2010) Sustainable urban transport plans (SUTPs). Brussels.

36. Tsay S-P, Herrmann V (2013) Rethinking urban mobility: sustainable policies for the Century of the City. Edited: Carnegie Endowment for International Peace. Report. Washington DC

37. OECD (2011) Greening household behaviour. The role of public policy. OECD

38. Weber M (2012) The way forward for renewable energy policy in the US. Edited: WorldwatchInstitute. Retrieved February 24th, 2014, from: http://blogs.worldwatch.org/revolt/the-way-forward-forrenewable-energy-policy-in-the-us/

39. Worldbank (2014) Data on car ownership. Retrieved April 30th 2014 from: http://data.worldbank.org/indicator/IS.VEH.NVEH. P3?page $=6$

40. Yan X, Crookesb RJ (2010) Energy demand and emissions from road transportation vehicles in China. Prog Energy Combust Sci 36:651-676

41. Zhang J (2011) China's energy security: prospects, challenges, and opportunities. Edited: The Brookings Institution - Center for Northeast Asian Policy Studies (CNAPS). Washington D.C. 